\title{
Evaluation of the Antimicrobial Activity of Endophytic Fungus Isolated from Cocos nucifera (L.) Cotyledon against Medically-Important Pathogens
}

\author{
Byran N. Fuego', Kyla G. Romano1, Charlmaine D. Pinlac¹, Gary Antonio C. Lirio, ${ }^{1,2}$ \\ ${ }^{1}$ Major in Science, Department of Elementary and Secondary Education, College of Education, Polytechnic University of the \\ Philippines, Manila, Philippines \\ ${ }^{2}$ Institute for Science and Technology Research, Center for Life Sciences Research, Polytechnic University of the Philippines, \\ Manila, Philippines \\ Email: bybyfuegy@gmail.com
}

How to cite this paper: Fuego, B.N., Romano, K.G., Pinlac, C.D. and Lirio, G.A.C. (2021) Evaluation of the Antimicrobial Activity of Endophytic Fungus Isolated from Cocos nucifera (L.) Cotyledon against Medically-Important Pathogens. Journal of Biosciences and Medicines, 9, 86-97. https://doi.org/10.4236/jbm.2021.91007

Received: November 29, 2020

Accepted: January 24, 2021

Published: January 27, 2021

Copyright $\odot 2021$ by author(s) and Scientific Research Publishing Inc. This work is licensed under the Creative Commons Attribution International License (CC BY 4.0).

http://creativecommons.org/licenses/by/4.0/

(c) (i) Open Access

\begin{abstract}
The study aimed to evaluate the endophytic fungi isolated from Cocos nucifera (L.) cotyledon for their possible antimicrobial activity. A total of twelve endophytic fungal species were successfully isolated, from which five were selected and presumptively identified, including Aspergillus niger, Raffaelea $s p$., Aspergillus flavus, Cladosporium sp. and Pseudallescheria spp. based on their macro and microscopic characters. The agar blocks of actively growing pure culture were assessed for antibacterial activity against five human pathogenic bacterial and fungal strains: Escherichia coli (BIOTECH 1634), Bacillus subtilis (BIOTECH 1697), Staphylococcus aureus (BIOTECH 1592), Serratia marcescens (BIOTECH 1748), and Candida tropicalis (BIOTECH 2085). Among the selected five endophytic used for antimicrobial activity screening, the Raffaelea sp. (CN-EF 2) has shown a high zone of inhibition of $11 \mathrm{~mm}$ against Bacillus subtilis, $18 \mathrm{~mm}$ against Escherichia coli, $15 \mathrm{~mm}$ against Staphylococcus aureus, and $11 \mathrm{~mm}$ against Candida tropicalis. Correspondingly, Aspergillus niger (CN-EF 1 ) has shown a zone of inhibition of $16 \mathrm{~mm}$ against $C$. tropicalis. The endophytic fungus Raffaelea $s p$. was effective against all test organisms except for Serratia marcescens, while Aspergillus niger was only effective for pathogenic fungi $C$. albicans. Hence, further in-depth studies of the isolated endophytic fungi are needed to determine the mechanisms behind the endophytes' inhibitory effects.
\end{abstract}

\section{Keywords}

Endophytic Fungi, Antimicrobial Activity, Cocos nucifera L., Natural 
Product, Agar Plug Diffusion, Medically-Important Pathogens

\section{Introduction}

Infectious diseases caused by drug-resistant bacteria and fungi are escalating [1], which pose a challenge in medicine. The rise in the number of cases caused by drug-resistant bacteria and fungi is driven by various factors such as widespread and often inadequate use of antibiotics, poor hygienic conditions, a constant movement of travelers [2], and delayed diagnosis of infections. This problem propelled the scientific community to explore natural products' sources of antimicrobial activity [3]. Organic plants play an essential role in the growth of medicinal production. However, increased attention has been put on discovering antimicrobial compounds produced by some fungi strains found in different environments [4].

Endophytes are microorganisms found in plant tissues or within the plants [5]. The term endophytes are widely used for fungi found in plants, which colonize the inner sections of plant tissues [6]. Endophytic fungi predominantly exist in all plants living in the plant's internal part without causing negative effects [7]. Almost every plant species harbors endophytic organisms [8]. Endophytic microorganisms are secured by their host plant producing secondary bioactive compounds necessary for their application in the medical and food industries [9]. Fungal endophytes produce bioactive metabolites such as alkaloids, isocoumarins, lignans, lactones, phenylpropanoids, phenols, quinones, steroids, and terpenoids [10]. Endophytic microorganisms with metabolic products have been examined as helpful in combating various harmful disease-causing agents and are found to be a good source of antibiotics [11]. A recent comprehensive study has introduced Phaeosphaeria nodulispora sp. nov. as a new species of Coelomycetes [12] isolated from Cocos nucifera.

Popularly known as coconut, coco, coco-da-bahia, or coconut-of-the-beach, Cocos nucifera is an important member of the family Arecaceae (palm family) [13]. C. nucifera constituents have been found to possess certain biological effects, such as antioxidant, antimicrobial, antihelminthic, anti-inflammatory, antifungal, antinociceptive, and antitumor function [14]. The plant is originally from Southeast Asia and is one of the essential plants in the Philippines [15]. It is depicted as a "tree of life" due to the variety of coconut benefits to humans. Previous studies have partly confirmed some uses of the plant showing antiarthritic, antipyretic, antidiarrheal, analgesic, and hypoglycemic effect [16]. Due to the increasing production of coconut in the Philippines, the country is recognized as one of the major exporters of coconut worldwide, contributing to $3.6 \%$ of the country's gross value added (G.V.A.) in agriculture [17].

Due to the high production of coconut in the country, the researchers aimed to investigate the presence of endophytic fungi found in $C$. nucifera's cotyledon 
and explore their antimicrobial activity against pathogenic organisms. This research study could be the next important discovery in medicine, which could also be used as a reference for future researchers by providing valid and accurate data on the potential application of the fungi in natural product discovery.

\section{Methodology}

\subsection{Collection of Plant Samples}

Plant samples were obtained from Esmeris Coconut Farm, Daanghari Campground, Brgy. Ilayang San Roque, Liliw Laguna, the Philippines $\left(14.1364^{\circ} \mathrm{N}, 121.4399^{\circ} \mathrm{E}\right)$, at the foothill of Mt. Banahaw with an estimated 40 hectares of coconut area. Samples of Cocos nucifera were collected on January 12, 2020. The plant species were identified, authenticated, and maintained at the Center for Life Sciences Research of the Polytechnic University of the Philippines. Healthy and mature coconuts were carefully chosen for sampling. Each coconut cotyledon was packed separately in sterile polythene bags and deposited in a freezer; within 120 hours of collection, chilled samples were used to isolate endophytic fungi.

\subsection{Isolation of Endophytic Fungi}

Isolation of endophytic fungi from Cocos nucifera (L.) cotyledon was carried out using the method described by Petrini (1986) with modifications. First, the cotyledons were thoroughly washed with running tap water to remove any debris and then air-dried. They were then surface sterilized by cleaning them for $2 \mathrm{mi}$ nutes with $95 \%$ ethanol. After sterilization, each cotyledon was divided into 2 segments, cut into strips ( 4 bits per tissue/cotyledon) by a sterilized blade under aseptic condition, and placed on potato dextrose agar. All the plates were incubated until the growth of fungi emerged. The cotyledon strips for the growth of endophytic fungi were observed after three days. Hyphal tips emerging out of the plated segments were transferred for subculture immediately onto another potato dextrose agar (P.D.A.). The pure culture's fungal strains were preserved with proper labeling on potato dextrose agar at $23^{\circ} \mathrm{C}$ to $27^{\circ} \mathrm{C}$.

\subsection{Morphological Identification of Endophytic Fungi}

Slides prepared from cultures were stained with lactophenol cotton blue reagent to characterize the fungal isolates and examined with a brightfield and phasecontrast microscope [18]. Presumptive identification was done based on the morphological and colonial characteristics of the endophytic fungi.

\subsection{Selection of Test Organisms}

The antimicrobial activity of endophytic fungi was assessed using five common human pathogens. All the pathogenic samples were derived from the Center for Life Sciences Research of the Polytechnic University of the Philippines. Gram-positive Staphylococcus aureus (BIOTECH 1582) and Bacillus subtilis (BIOTECH 1697), Gram-negative Escherichia coli (BIOTECH 1634), and 
Serratia marcescens (BIOTECH 1748), and pathogenic yeast Candida tropicalis (BIOTECH 2085) were used for this study. Using the subculturing technique, the selected microbial cultures were preserved. Mueller Hinton broth was used for the cultivation of microbial cultures.

\subsection{Evaluation of Antimicrobial Activity of Endophytic Fungi}

Agar blocks of endophytic fungi were screened for their antimicrobial activity using an agar plug diffusion test with five reference human pathogenic microorganisms. In this method, pathogens' cultures were adjusted to $1.5 \times 10^{8}$ colony forming units (CFU) per milliliter based on 0.5 McFarland turbidity standards. The standardized microbial strains were immediately streaked using sterile cotton swabs into the prepared Mueller Hinton agar plates. Then, $8 \mathrm{~mm}$ of wells were made aseptically using sterile cork borer in the seeded media, and appropriate agar blocks of actively growing pure culture were dropped in the prepared wells. The plates were allowed to stand undisturbed for an hour to allow proper absorption into the medium and incubated in a bacteriological incubator for 24 hours at $35^{\circ} \mathrm{C}$. The positive (Ofloxacin, Rifampicin, Penicillin, and Trimethoprim) and negative controls for each pathogen were prepared separately. Plates were observed for inhibition zones, and their diameter was measured and compared with the control using the Vernier scale. Three replicates were maintained in different cases, and the results were expressed as mean \pm SD.

\subsection{Biochemical Characterization}

The selected endophytic fungi were subjected to various biochemical tests, and the individual results were recorded. The biochemical tests that were used to identify the unknown cultures were Casein Hydrolysis Test, Starch Hydrolysis Test, and Urease Test.

\subsection{Data Analysis}

The zone of inhibition results was interpreted as means $(\mathrm{n}=3)$ and analyzed for possible significant difference among the treatments and controls using Single-Factor Analysis of Variance (ANOVA) at 0.05 level of significance [19].

\section{Results}

\subsection{Isolation of Endophytic Fungi}

C. nucifera samples were collected from Esmeris Farm, Daanghari Campground. Totally, 20 segments ( 4 strips per cotyledon/plate) were screened for isolating endophytic fungi. From 20 tissue segments, 12 isolates were obtained from $C$. nucifera cotyledon, and all were stained by lactophenol cotton blue and observed under a brightfield microscope shown in Figure 1. A total of five endophytic fungi have been selected for screening antimicrobial activity against human pathogens in the present study. Table 1 indicates the selected endophytic fungi. 


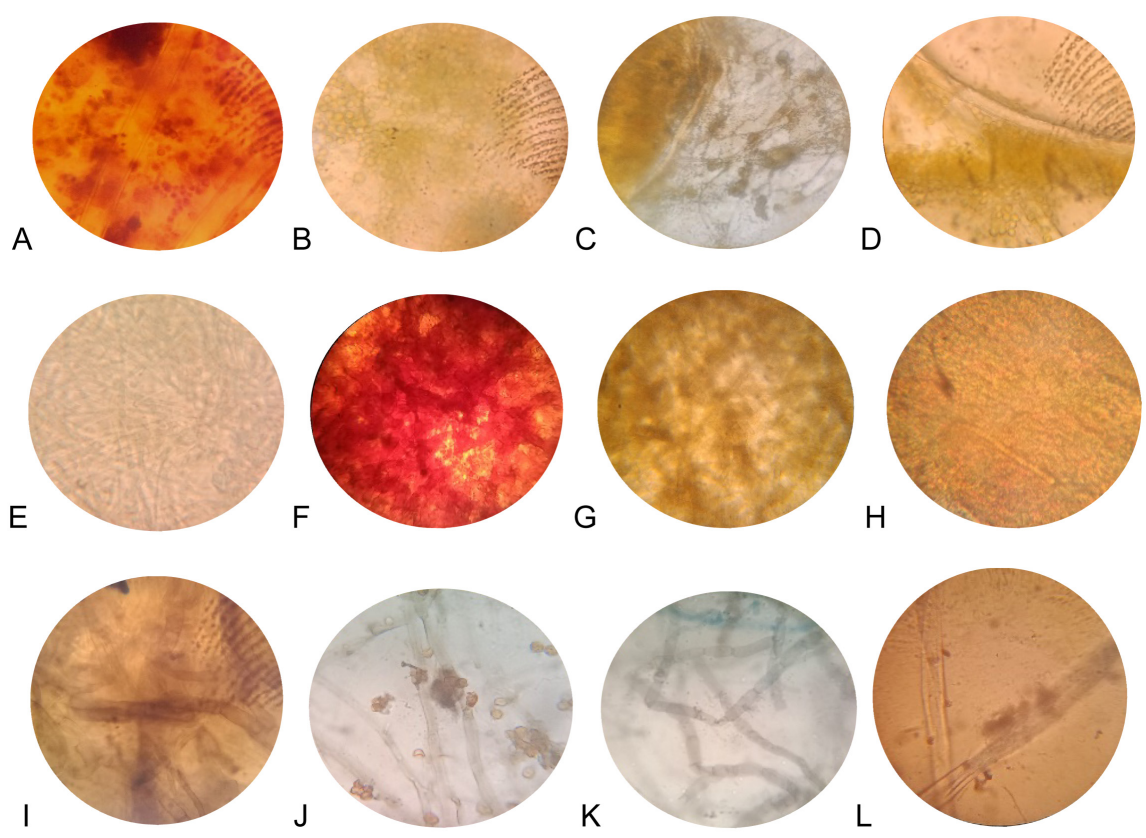

Figure 1. Endophytic fungi observed under the microscope.

Table 1. The selected endophytic fungi.

\begin{tabular}{cc}
\hline Strain Code & Strain Name \\
\hline CN-EF 1 & Aspergillus niger \\
CN-EF 2 & Raffaelea sp. \\
CN-EF 3 & Aspergillus flavus \\
CN-EF 4 & Cladosporium $s p$. \\
CN-EF 5 & Pseudallescheria sp. \\
\hline
\end{tabular}

\subsection{Evaluation of Antimicrobial Activity}

Agar blocks of actively growing pure culture were tested against the bacterial and fungal pathogens by the plug diffusion method. Totally, 5 microorganisms, which consisted of 4 bacteria and 1 fungus, were tested. The agar blocks were assayed against the test organisms; the zones of inhibition obtained were between 11 and $18 \mathrm{~mm}$. It was observed that the agar blocks of endophytic fungi isolated from Cocos nucifera L., including the antibiotic controls, inhibited the human pathogens presented in Figures 2-6. The preliminary screening test results are summarized in Table 2, which revealed that endophytic fungi species possessed antibacterial and antifungal activity.

The agar plug diffusion method was performed by screening endophytic fungi to assess the antimicrobial activity against 5 pathogenic human bacterial and fungal strains. CN-EF 2 showed a high zone of inhibitions of $11 \mathrm{~mm}$ against $B$. subtilis, $18 \mathrm{~mm}$ against $E$. coli, $15 \mathrm{~mm}$ against $S$. aureus, and $11 \mathrm{~mm}$ against $C$. tropicalis. $\mathrm{CN}-\mathrm{EF} 1$ also showed a zone of inhibition of $16 \mathrm{~mm}$ against C. tropicalis. 


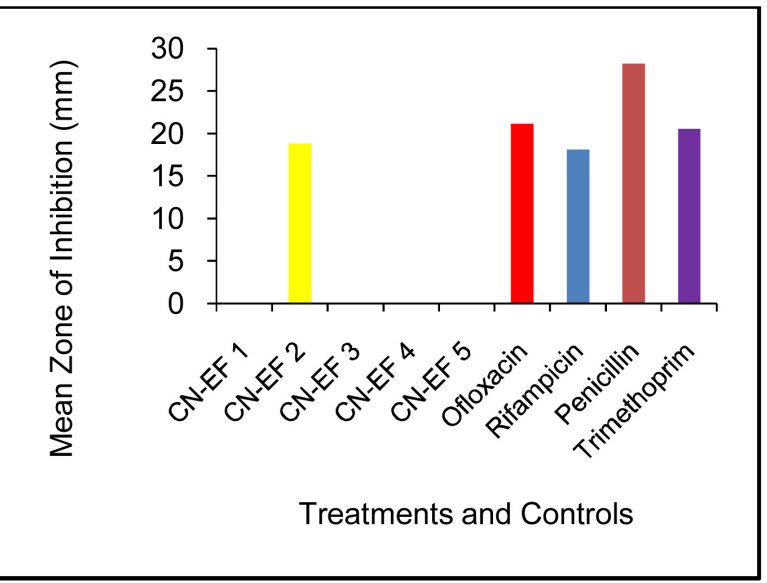

Figure 2. Antibacterial activity of the endophytic fungi isolated from Cocos nucifera (L.) cotyledon against E. coli. (All values are interpreted as mean; $\mathrm{n}=3$ ).

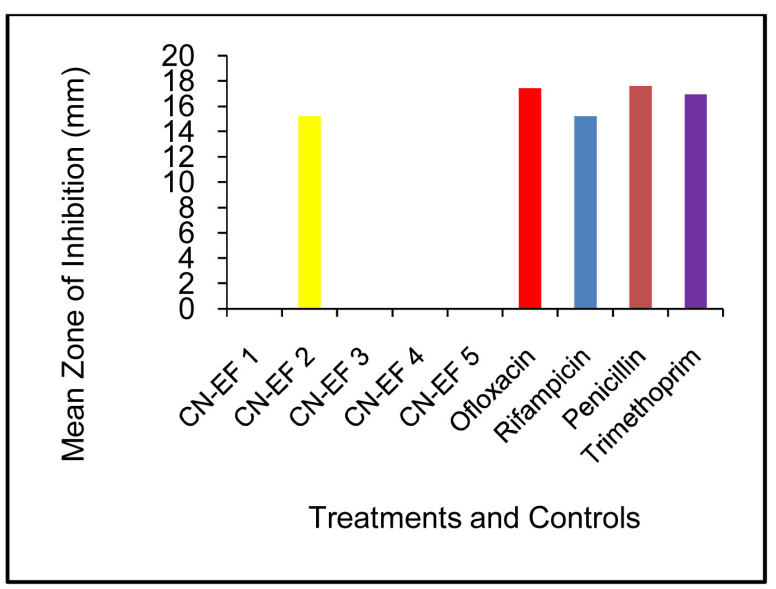

Figure 3. Antibacterial activity of the endophytic fungi isolated from Cocos nucifera (L.) cotyledon against $S$. aureus. (All values are interpreted as mean; $\mathrm{n}=3$ ).

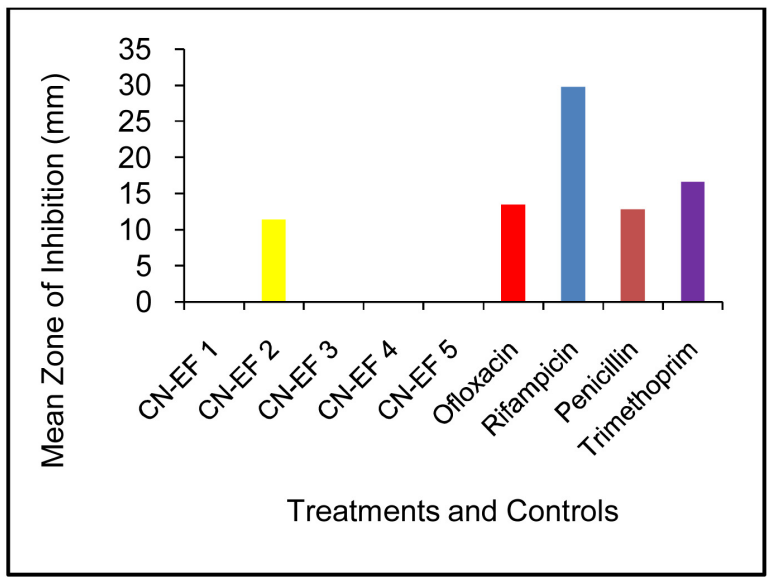

Figure 4. Antibacterial activity of the endophytic fungi isolated from Cocos nucifera (L.) cotyledon against B. subtilis. (All values are interpreted as mean; $\mathrm{n}=3$ ). 


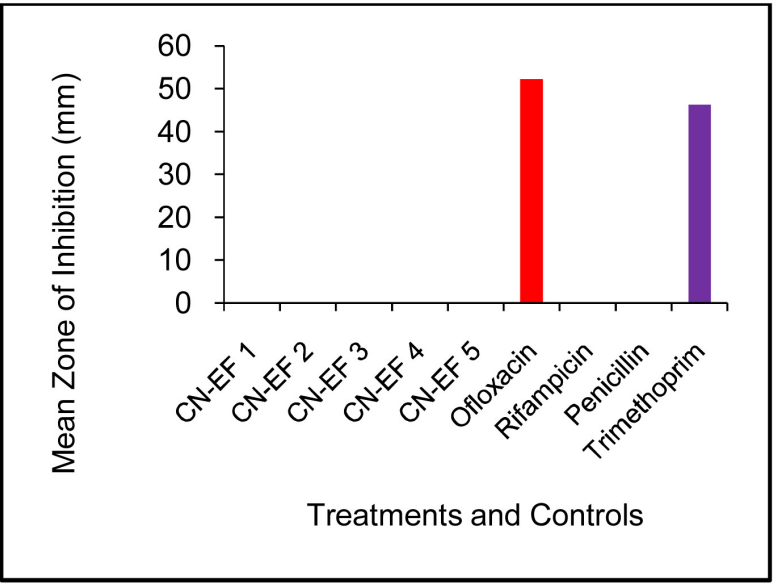

Figure 5. Antibacterial activity of the endophytic fungi isolated from Cocos nucifera (L.) cotyledon against $S$. marcescens. (All values are interpreted as mean; $\mathrm{n}=3$ ).

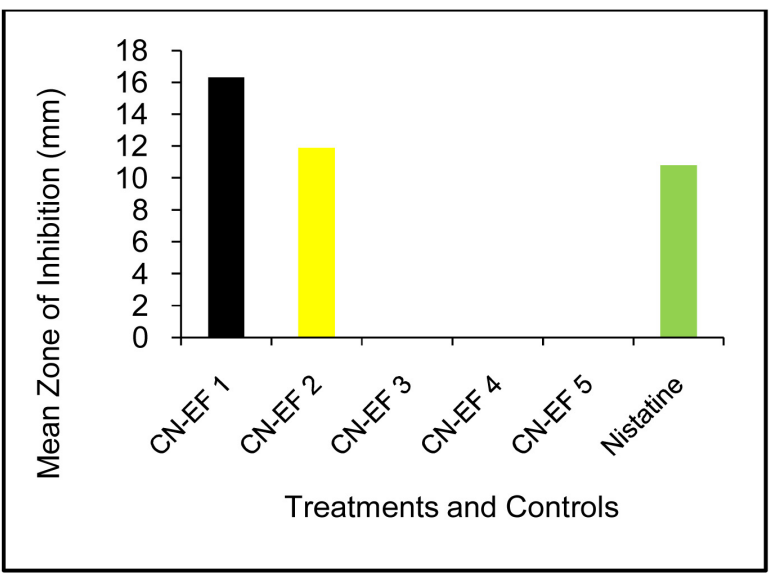

Figure 6. Antifungal activity of the endophytic fungi isolated from Cocos nucifera (L.) cotyledon against $C$. tropicalis. (All values are interpreted as mean; $\mathrm{n}=3$ ).

Table 2. Summary table of susceptibility test of endophytic fungi and controls against medically-important pathogens.

\begin{tabular}{|c|c|c|c|c|c|c|c|c|c|c|c|c|}
\hline \multirow{3}{*}{$\begin{array}{l}\text { Human } \\
\text { Pathogens }\end{array}$} & \multicolumn{10}{|c|}{ Zone of Inhibition (mm) } & \multirow{3}{*}{$\mathrm{p}$-value } & \multirow{3}{*}{ Interpretation } \\
\hline & \multicolumn{5}{|c|}{ Treatments } & \multicolumn{5}{|c|}{ Controls } & & \\
\hline & $\begin{array}{c}\text { CN-EF } \\
1\end{array}$ & $\begin{array}{c}\text { CN-EF } \\
2\end{array}$ & $\begin{array}{c}\text { CN-EF } \\
3\end{array}$ & $\begin{array}{c}\text { CN-EF } \\
4\end{array}$ & $\begin{array}{c}\mathrm{CN}-\mathrm{EF} \\
5\end{array}$ & $\mathrm{O}$ & $\mathbf{R}$ & $\mathrm{T}$ & $\mathbf{P}$ & $\mathbf{N}$ & & \\
\hline B. subtilis & - & $11.4 \pm 0.4$ & - & - & - & $13.5 \pm 0.1$ & $29.8 \pm 0.3$ & $316.6 \pm 0.7$ & $12.8 \pm 0.5$ & NA & $2.62 \mathrm{E}-12$ & $\begin{array}{l}\text { Significantly } \\
\text { different }\end{array}$ \\
\hline E. coli & - & $18.8 \pm 4.3$ & - & - & - & $21.1 \pm 0.05$ & $\begin{array}{c}18.1 \pm \\
0.05\end{array}$ & $20.5 \pm 0.052$ & $28.1 \pm 0.005$ & NA & 0.0006 & $\begin{array}{l}\text { Significantly } \\
\text { different }\end{array}$ \\
\hline S. aureus & - & $15.2 \pm 3.6$ & - & - & - & $17.4 \pm 0.5$ & $15.1 \pm 0.9$ & $916.9 \pm 1.4$ & $17.6 \pm 3.5$ & NA & 0.598 & $\begin{array}{c}\text { Not significantly } \\
\text { different }\end{array}$ \\
\hline S. marcescens & - & - & - & - & - & $52.2 \pm 3.8$ & - & $46.2 \pm 8$ & - & NA & - & - \\
\hline C. tropicalis & $16.3 \pm 0.2$ & $11.9 \pm 2.5$ & - & - & - & NA & NA & NA & NA & $10.8 \pm 1.7$ & 0.0197 & $\begin{array}{l}\text { Significantly } \\
\text { different }\end{array}$ \\
\hline
\end{tabular}

Values are averages of three replicates \pm S.D., O-Ofloxacin, R-Rifampicin, T-Trimethoprim, P-Penicillin, N-Nystatin, NA-Not Available. 


\subsection{Biochemical Characterization of Endophytic Fungi}

The result of the various biochemical tests performed to identify the isolates was shown in Table 3.

$\mathrm{CN}-\mathrm{EF}$ 1, CN-EF 3, and CN-EF 5 shown in Figure 7 were found to hydrolyze starch, hence, amylase positive while the others are all negative. CN-EF 2 and CN-EF 4 showed a positive result for the Casein Hydrolysis Test; these isolates could degrade casein protein (Figure 8). It is also found out that three species showed a positive urease test by the development of magenta or bright pink color while the others do not react (Figure 9).

Table 3. Cumulative result of biochemical tests.

\begin{tabular}{cccc}
\hline \multirow{2}{*}{$\begin{array}{c}\text { Endophytic } \\
\text { Fungi }\end{array}$} & Biochemical Test \\
\cline { 2 - 4 } CN-EF 1 & Casein Hydrolysis Test & Starch Hydrolysis Test & Urease Test \\
\hline CN-EF 2 & + & - & - \\
CN-EF 3 & - & + & + \\
CN-EF 4 & + & - & + \\
CN-EF 5 & - & + & - \\
\hline
\end{tabular}

(+) positive result, (-) negative result.

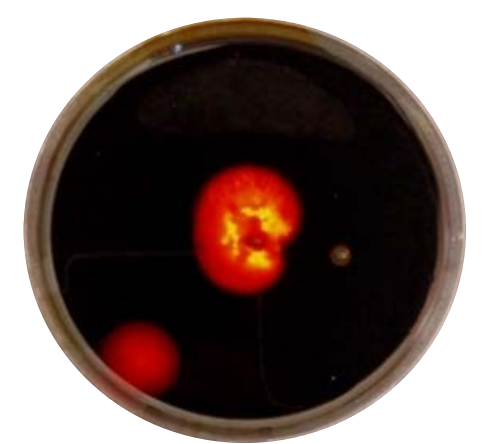

Figure 7. After adding the iodine solution, CN-EF 5 showed a clear zone around the colony that manifests a positive amylase production test.

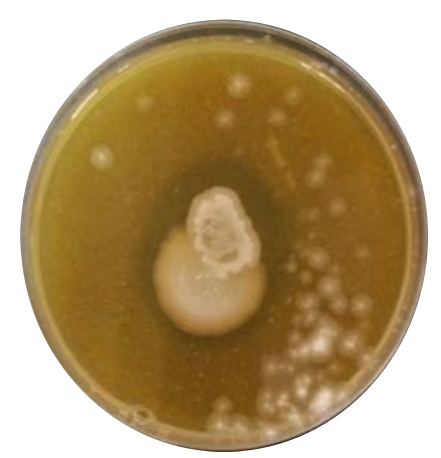

Figure 8. A clear zone around the fungal growth of CN-EF 2 shows a positive caseinase production test. 


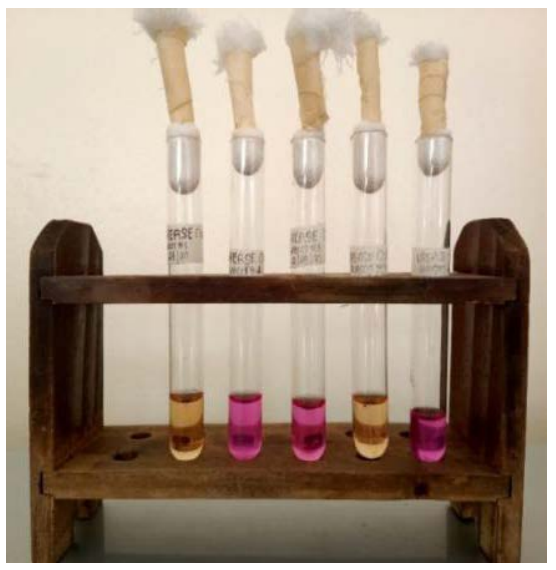

Figure 9. Positive and negative results for the Urease test. Development of intense bright pinkcolor shows positive urease production.

\section{Discussion}

Antimicrobial properties are significantly important to public health, particularly in reducing the growth of harmful microorganisms and restraint the transmission of bacterium. These antimicrobial compounds can be developed in endophytic fungi [20]. A recent study shows that the fungi endophytes are a source of medicinal compounds due to taxol discovery, a popular anticancer drug [21]. Endophytes have attracted interest in the research field due to their potential to generate novel bioactive compounds [22]. Concerning the statement, compounds found in endophytic fungi may have distinctive mechanisms and perplexing bio-activities, comprising a high proportion offering enormous opportunity for a research study. A research study reveals that endophytic fungi isolated in leaves of Euphorbia hirta showed a broad spectrum of antimicrobial activity against human pathogens [23].

Due to the fungal endophytes' antimicrobial activity, researchers utilize endophytic fungi isolated from the Cocos nucifera cotyledon to observed potential antibacterial and antifungal activity. A research study conducted shows the endophytic fungi isolated in leaves, roots, and petiole of palm trees, namely Phoma exigua, Fusarium chamydosporum, Phialophora spp. and Nigrospora spp. was proved to have biological activity against Colletotrichum coffeanum [24], a fungal plant pathogen causing coffee anthracnose. Another research study reported that the fungal endophytes isolated from palm oil control the Ganoderma [25].

It was observed that agar blocks of actively growing pure culture isolated showed antibacterial activity against Gram-positive and Gram-negative bacteria. The result of this study is similar to the result of previous studies conducted using the same method. A research study has shown that using agar plug diffusion found promising antimicrobial activity of mycoendophytes designated as TS071, TS073, DH182, DH221, and DH223 against human pathogenic bacteria, specifically $E$. coli and B. subtilis. These findings indicate the progress of identifying and characterizing antimicrobial compounds from bioactive elements of endo- 
phytic fungi [26].

The present investigation showed maximum susceptibility of human pathogens to endophytic fungi, which could be attributed to the bioactive metabolites produced by fungi species. A research study has shown that bioactive compounds, organic acids, various enzyme inhibitors, antihelmintics, antitumor agents, insecticides, vitamins, immunosuppressants, and immunomodulators are widely reported found in the members of the Aspergillus genus [27].

\section{Conclusion}

In the present study, a total of 12 endophytic fungi were isolated from the Cocos nucifera (L.) cotyledon. Two out of the five selected endophytic fungi chosen for screening antimicrobial activity showed a maximum zone of inhibitions against B. subtilis, S. aureus, E. coli, and C. tropicalis. Further studies are needed for these isolated endophytes. To help produce a particular bioactive compound, one may further grow them on a large scale, modify culture conditions, and supply stimulants.

\section{Recommendation}

This is probably the first study that evaluated the antimicrobial activity of endophytic fungi isolated from Cocos nucifera L. cotyledon, collected from Esmeris Farm, Daanghari Campground, Laguna, Philippines. The successful isolation of these endophytes suggests that they shall be identified through molecular methods to determine the identity of the fungi to the species level. Moreover, further studies shall be conducted to determine the pathogenicity of the endophytic fungi and unravel their potential application in the clinical setting.

\section{Conflicts of Interest}

The authors declare no conflicts of interest regarding the publication of this paper.

\section{References}

[1] Firáková, S.H., Sturdikova, M. and Múčková, M. (2007) Bioactive Secondary Metabolites Produced by Microorganisms Associated with Plants. Biologia, 62, 251-257. https://doi.org/10.2478/s11756-007-0044-1

[2] Dos Santos, I.P., Da Silva, L.C.N., Da Silva, M.V., De Araujo, J.M., Cavalcanti, M.S. and De Menezes Lima, V.L. (2015) Antibacterial Activity of Endophytic Fungi from Leaves of Indigofera suffruticosa Miller (Fabaceae). Frontiers in Microbiology, 6, 350. http://creativecommons.org/licenses/by/3.0/ https://doi.org/10.3389/fmicb.2015.00350

[3] Gangwar, M., Verma, V.C., Gautam, M. and Nath, G. (2015) Isolation and Evaluation of Antimicrobial Activities of Endophytic Fungal Extract from Mallotus philippinensis Muell. Applied Microbiology: Open Access, 1, 1000103. https://doi.org/10.4172/2471-9315.1000103

[4] Nuthan, B.R., Swamy, M.S., Satish, S. and Ramesha, K.P. (2016) Antimicrobial Activity of Mycoendophytes Inhabiting Selected Epiphytic Plants of the Western 
Ghats. https://www.researchgate.net/publication/339089372

[5] Nair, D.N. and Padmavathy, S. (2014) Impact of Endophytic Microorganisms on Plants, Environment and Humans. The Scientific World Journal, 2014, Article ID: 250693. https://doi.org/10.1155/2014/250693

[6] Morales, N., Hasan, A., To, H., Lekaduo, T., Copeland, J., Wang, P., Diallo, H., Konan, J., Yoshioka, K., Moeder, W., Scott, J. and Rosete, Y.A. (2017) Microbial Diversity in Leaves, Trunk and Rhizosphere of Coconut Palms (Cocos nucifera L.) Associated with the Coconut Lethal Yellowing Phytoplasma in Grand-Lahou, Côte d'Ivoire. Academic Journals. http://creativecommons.org/licenses/by/3.0/

[7] Gond, S.K., Mishra, A., Sharma, V.K., Verma, S.K., Kumar, J., Kahrwar, R.N. and Kumar, A. (2013) Diversity and Antimicrobial Activity of Endophytic Fungi Isolated from Nyctanthes arbor-tristis, a Well-Known Medicinal Plant of India. Mycoscience, 53, 113-121.

[8] Beiranvand, M., Amin, M., Hashemi-Shahraki, A., Romani, B., Yaghoubi, S. and Sadeghi, P. (2017) Antimicrobial Activity of Endophytic Bacterial Populations Isolated from Medicinal Plants of Iran. Iranian Journal of Microbiology, 9, 11-18.

[9] Dhayanithy, G., Subban, K. and Chelliah, J. (2019) Diversity and Biological Activities of Endophytic Fungi Associated with Catharanthus roseus. BMC Microbiology, 19, Article No. 22. https://doi.org/10.1186/s12866-019-1386-x

[10] Hamzah, T.N.T., Lee, S.Y., Hidayat, A., Terhem, R., Faridah-Hanum, I. and Mohamed, R. (2018) Diversity and Characterization of Endophytic Fungi Isolated From the Tropical Mangrove Species, Rhizophora mucronata, and Identification of Potential Antagonists Against the Soil-Borne Fungus, Fusarium solani. Frontiers in Microbiology, 9, 1707. https://doi.org/10.3389/fmicb.2018.01707

[11] Hardoim, P.R., Van Overbeek, L.S., Berg, G., Pirttilä, A.M., Compant, S., Campisano, A., Döring, M. and Sessitsch, A. (2015) The Hidden World within Plants: Ecological and Evolutionary Considerations for Defining Functioning of Microbial Endophytes. Microbiology and Molecular Biology Reviews, 79, 293-320. https://doi.org/10.1128/MMBR.00050-14

[12] de Oliveria, R.J.V., Bezerra, J.L., Lima, T.M.F., da Silva, G.A. and Cavalcanti, M.A.Q. (2016) Phaeosphaeria nodulispora, a New Endophytic Coelomycete Isolated from Tropical Palm (Cocos nucifera) in Brazil. Nova Hedwigia, 103, 185-192.

[13] Lima, E.B.C., Sousa, C.N.S., Meneses, L.N., Ximenes, N.C., Santos Jr., M.A., Vasconcelos, G.S., Lima, N.B.C., Patrocínio, M.C.A., Macedo, D. and Vasconcelos, S.M.M. (2015) Cocos nucifera (L.) (Arecaceae): A Phytochemical and Pharmacological Review. Brazilian Journal of Medical and Biological Research, 48, 953-964. https://pubmed.ncbi.nlm.nih.gov/26292222/

[14] Castillo, M.B. and Ani, P.A.B. (2019) The Philippine Coconut Industry: Status, Policies, and Strategic Directions for Development. FFTC Agricultural Policy Platform. https://ap.fftc.org.tw/article/1382

[15] Dayrit, F.M. (2005) A Brief History of the Philippine Coconut Industry. DOST SciNET-PHIL. http://scinet.dost.gov.ph

[16] Chia, S.Y. (2013) The ASEAN Economic Community: Progress Challenges, and Prospects. ADBI Institute.

https://www.adb.org/publications/asean-economic-community-progress-challenges -and-prospects https://doi.org/10.2139/ssrn.2346058

[17] Philippine Statistics Authority (2019) Data on Coconut Production, Yield, and Area Planted. CountrySat PSA. http://countrystat.psa.gov.ph 
[18] Barnet, H.L. and Hunter, B.B. (1998) Illustrated Genera of Imperfect Fungi. 4th Edition, APS Press, 218. http://apspress.edu.com

[19] Ureta, R.M., Lirio, G.A.C., Ogbac, M.P.N., Cruzado, Z.I.A. and Muros, E.L.B. (2019) Antibacterial Activity of the Lyophilized Aqueous Leaf Extract of the Philippine Green-Leafed Acalypha amentacea Roxb. (Maslakot-Ambulong) against Selected Human Bacterial Pathogens. Malaysian Journal of Microbiology, 15, 463-470. https://doi.org/10.21161/mjm.180323

[20] Chi, W.C., Pang, K.L., Chen, W.L., Wang, G.J. and Lee, T.H. (2019) Antimicrobial and iNOS Inhibitory Activities of the Endophytic Fungi Isolated from the Mangrove plant Acanthus ilicifolius var. xiamenensis. Botanical Studies, 60, Article No. 4. http://creativecommons.org/licenses/by/4.0/ https://doi.org/10.1186/s40529-019-0252-3

[21] Chetia, H., Kabiraj, D., Bharali, B., Ojha, S., Barkataki, M.P., Saikia, D., Singh, T., Mosahari, P.V., Sharma, P. and Bora, U. (2019) Exploring the Benefits of Endophytic Fungi via Omics. In: Singh, B., Ed., Advances in Endophytic Fungal Research. Fungal Biology, Springer, Cham, 51-81. https://doi.org/10.1007/978-3-030-03589-1 4

[22] Bhuju, D., Boonchird, C., Koirala, M. and Rana, P. (2017) Impact of Altitude on the Colonization Frequency of Endophytic Fungi Isolated from Rhododendron campanulatum D. Don of Sagarmatha National Park, Nepal. Journal of Basic and Applied Polymer Science, 1, 36000109. http://creativecommons.org/licenses/by/3.0/

[23] Akpotu, M.O., Eze, P.M., Ajaghaku, D.L., Okoye, F. and Esimone, C.O. (2017) Antimicrobial Activity of Endophytic Fungi Isolated from Catharanthus roseus and Euphorbia hirta. Planta Medica, 81, No. 16. http://creativecommons.org/licenses/by/3.0/

[24] Song, J.J., Wattanachai, P. and Kasem, S. (2015) Biological Activity of Endophytic Fungi from Palm Trees against Chili Anthracnose Caused by Colletotrichum capsici. Journal of Agricultural Technology, 11, 1927-1940. http://www.ijat-aatsea.com/

[25] Pinruan, U., Rungjindamai, N., Choeyklin, R., Lumyong, S., Hyde, K.D. and Jones, E.B. (2010) Occurrence and Diversity of Basidiomycetous endophytes from the Oil Palm, Elaeis guineensis in Thailand. Fungal Diversity, 41, 71-88.

https://www.researchgate.net/publication/227300243 https://doi.org/10.1007/s13225-010-0029-1

[26] Mylonakis, E., Podsiadlowski, L., Muhhammed, M. and Vilcinskas, A. (2016) Diversity, Evolution and Medical Applications of Insect Antimicrobial Peptides. Philosophical Transactions of the Royal Society B: Biological Sciences, 371, 20150290. https://www.ncbi.nlm.nih.gov/pmc/articles/PMC4874388/

[27] Jabeen, N., Shafique, M., Naz, S.A., Versiani, M.A. and Jawaid, K. (2019) Bioactive Metabolites from Aspergillus terreus MK-1. Abstract Books. 